\title{
Shift-Work-Play: Understanding the positive and negative experiences of male and female shift workers to inform opportunities for intervention to improve health and wellbeing
}

\author{
AUTHORS \\ ROWAN P OGEIL PhD $1,2,3$ \\ MICHAEL SAVIC PhD1,2,3 \\ NYSSA FERGUSON $\mathrm{MPH}^{2,4}$ \\ DAN I LUBMAN PhD',2,3
}

1 Eastern Health Clinical School, Monash University, Box Hill, Victoria, Australia.

2 Turning Point, Eastern Health, Richmond, Victoria, Australia.

3 Monash Addiction Research Centre, Frankston, Victoria, Australia.

4 National Drug Research Institute, Curtin University, Fitzroy, Victoria, Australia.

\section{CORRESPONDING AUTHOR}

ROWAN P OGEIL Monash University and Turning Point, 110 Church Street, Richmond, Victoria, Australia, 3121. Phone: +613-8413 8469. Email: rowan.ogeil@monash.edu

\section{ABSTRACT}

Objective: Our primary study aims are to (i) examine positive and negative aspects associated with shift work, and (ii) identify any gender differences that exist in a healthcare workforce. A secondary aim of the study was to identify opportunities for intervention, particularly in males given they have greater exposure to shift work across the population.

Background: Shift work has been associated with detrimental physical and psychosocial outcomes in many studies; however, there has been little consideration of any positive perceived aspects associated with shift work. Additionally, while there has been less consideration of gender differences in medical settings such as nursing where there is a higher proportion of females working shifts.

Study design and methods: Our study utilised mixed-methods, comprising a cross-sectional workforce survey given to both shift workers and non-shift workers ( $\mathrm{N}=1398)$, and a co-design workshop aimed at male nurses, in order to identify opportunities for intervention among this group.
Results: Shift workers were more likely than their non-shift work counterparts to report poorer overall health, to have higher levels of psychological distress, and to engage in greater levels of unhealthy behaviours (e.g. higher alcohol consumption, and greater levels of smoking), with these differences highest in male shift workers.

Discussion: Analysis of the shift work experience revealed that the majority of responses were negative (affecting sleep, diet, exercise, mental health), however one-in-five statements were positive with flexibility, and the ability to engage with services highlighted. Examining both positive and negative elements is important for providing a balanced insight into shift workers' lives, and to inform targets for improving their health and wellbeing.

Conclusion: Through identifying positive and negative elements associated with shift work it is possible to intervene to minimise the negative elements, and maximise positive elements. Our analysis highlights the importance of considering gender differences in both individual and organisational-level responses. 
Implications for research, policy, and practice: To effectively address the negative aspects of shift work, interventions at multiple levels involving both organisations and individuals that simultaneously target multiple outcomes (sleep, diet, exercise, opportunities to connect with peers) are likely to be more effective than individual measures alone.

\section{What is known about the topic?}

- Shift work is common across many different industries, and is an integral part of the nursing profession, where nurses and midwives make up almost $50 \%$ of the worldwide shift working workforce.

- Shift work has been associated with negative impacts on individual physical and psychological health and performance outcomes such as increased error rates.
What this paper adds:

- This study confirms that shift work is associated with negative impacts however there are positive elements associated with shift work and these include flexibility and financial benefits.

- Gender differences were apparent with risky alcohol use, higher smoking rates, and poorer health noted in males compared with females.

- Our co-design workshop identified the potential for a holistic response based on the three pillars of health: sleep, diet and exercise as likely to be more effective than an intervention addressing only one of these domains.

Keywords: Shift work, nurses, survey, co-design, gender

\section{OBJECTIVE}

Recent decades have seen increases in the proportion of the population engaged in employment outside of the traditional nine-to-five day in many jurisdictions including Australia and North America. ${ }^{1,2}$ Approximately 20\% of the worldwide labour force are classified as shift workers, with this work pattern common across many industries including health, ${ }^{3}$ mining, 4 and transport. ${ }^{5}$ Shift work is an integral part of the nursing profession, and nurses and midwives make up almost 50\% of the worldwide shift working workforce, ${ }^{6}$ which is important given that nurses provide care to patients $24 \mathrm{~h}$ a day, seven days a week.7 Shift work negatively impacts on both the health and wellbeing of individuals, and also their performance. ${ }^{8,9}$ For example, a New Zealand study reported that both shift timing and sleep history were predictive of fatigue-related errors in the past six months. ${ }^{10}$ It is therefore important to identify opportunities to intervene to minimise performance decrements given that errors made in hospital and nursing environments can impact on patient care and recovery. ${ }^{11}$

This paper presents the findings of a mixed-methods study comprising a workforce survey of staff at a metropolitan hospital in Melbourne, Victoria, and a subsequent codesign workshop aimed at identifying positive and negative elements of shift work and relevant gender differences, and using these to identify opportunities for intervention to improve the lives of shift workers.

\section{BACKGROUND}

\section{SHIFT WORK AND ADVERSE OUTCOMES}

Shift work presents a challenge to underlying human physiology, which has biologically adapted to the light- dark cycle. ${ }^{12}$ Opposing the endogenous circadian drive is detrimental to an individual's physical and psychosocial health. ${ }^{13}$ For example, shift workers have a higher incidence of obesity, ${ }^{14}$ type II diabetes, ${ }^{15}$ decreased mental health, ${ }^{16}$ and increased isolation, ${ }^{7,17,18}$ when compared with day workers. These negative outcomes have been attributed to multiple mechanisms including poor sleep quality and quantity, increased stress, and the adoption of unhealthy lifestyle factors. ${ }^{17}$

In addition to direct health effects, shift work also affects employee productivity and performance, ${ }^{19}$ being associated with an increase in adverse events and employee absenteeism. ${ }^{20}$ Outside of the work environment, shift workers have reported feeling isolated, ${ }^{21}$ and experiencing disrupted social lives, particularly in balancing work/life demands. ${ }^{2}$ Together, these health, occupational and social outcomes have implications for an individual's emotional and social welfare. ${ }^{7,17}$ Opportunities for shift workers to participate in health-promoting and/or social activities outside of their workplace may also be adversely affected by irregular work schedules and sleep patterns. ${ }^{22}$

Despite the plethora of negative outcomes associated with shift work, other researchers have suggested that some individuals are better able to adapt to shift work without experiencing adverse consequences. Individual personality factors including greater flexibility, low neuroticism, high extraversion, and an internal locus of control were associated with higher tolerance to shift work, ${ }^{23,24}$ with one prospective study in nurses identifying that hardiness predicted increased tolerance to shift work across a two year period, ${ }^{25}$ and another recommending that nurses' attitudes toward rotating shift work (objectionable, constructive or ambivalent) be taken into account with respect to organisational roster design. ${ }^{26}$ 
Others studies have noted that increased organisational support (e.g. greater collegiality between staff), ${ }^{27}$ and shift structuring (e.g. in terms of the direction of the rotation pattern, number of consecutive night shifts, opportunities to promote cohesion between workers), and food and beverage intake patterns by shift workers may reduce negative health outcomes associated with shift work. ${ }^{21}$

While males have greater exposure to shift work across the population, ${ }^{28}$ this differs in some medical settings such as nursing given the higher proportion of females employed as nurses. While some studies have reported increased tolerance to the deleterious effects of shift work in males, ${ }^{24}$ this is largely dependent on occupation and role. For example, Tuckett and colleagues reported that male nurses tended to have poorer clinical outcomes (greater BMI and cardiovascular symptoms, to be more sedentary, report poorer sleep, and were more likely to smoke, while women reported greater levels of feeling worn out), ${ }^{29}$ and in a comparative analysis across different occupations male nurses reported the highest rates of sick leave. ${ }^{30}$ Gender differences in the context of shift work may be compounded given that males typically report greater social isolation, ${ }^{31}$ and social connection is an important factor protective against suicide, depression, and anxiety, and is particularly relevant for men who are overrepresented in suicide statistics. Hence, the present paper specifically examines the experiences of male and female shift workers, with the goal to inform opportunities for intervention to improve health and wellbeing.

While research has focussed on negative health and productivity costs associated with shift work, there has been little consideration of the perceived positive aspects associated with shift-work gained from male and female shift workers themselves. Examining both positive and negative elements together is important for providing a balanced insight into shift workers' lives, and to inform targets for improving their health and wellbeing. Given that effective interventions have been argued to be context dependent, especially in healthcare settings ${ }^{18}$ this study considers shift workers in a metropolitan health network.

\section{METHODS}

This study utilised a mixed-methods design, comprising a workforce survey (given to both shift workers and non-shift workers) and a subsequent co-design workshop aimed at male nurses to discuss their reflections on the survey results and identify opportunities for intervention.

\section{SURVEY}

Participants were recruited from a major metropolitan health service in Melbourne, Australia, which oversees three major hospitals and multiple outpatient clinics and services. Participants were invited to complete a workforce survey, which received approval from the Eastern Health
Human Research Ethics Committee (LR91-2016). Invitations to participate were sent via email messages, and were included on employee payslips and newsletters sent by HR and senior management. Prior to beginning the survey, a written description of the project, a hyperlink to the online survey, and contact details of researchers was provided to participants. The email invitation was sent from a generic hospital address to minimise any perceived personal relationships and/or perceived coercion to participate from senior management. Participants who completed the survey were not provided with a direct incentive, however were entered into a prize draw to win one of ten gift vouchers (worth AUD\$100 each).

\section{CO-DESIGN WORKSHOP}

Following completion of the survey, the authors ran a half-day co-design workshop, with five male nurses to: (a) explore how well the survey results reflected their individual experiences and reality of shift work; (b) examine the impacts of shift work on social connectedness and isolation; and (c) identify opportunities for intervention to overcome negative effects of shift work.

Co-design is a process that enables communities - in this case male shift workers - to participate in design processes through the workshopping of ideas that could be developed to meet the needs of communities. As such, co-design workshops are increasingly being employed and documented in healthcare and health promotion practice and research..$^{32,33}$ Staff were selected by the organisation's Chief Nursing and Midwifery Officer to represent junior and senior male nursing staff from across the organisation, and the co-design workshop was facilitated by the Consumer Participation \& Patient Experience office of Eastern Health. The co-design workshop was targeted towards male participants given that our survey results revealed that they were more likely to be negatively affected by shift work than females, and are useful given that the majority of qualitative survey responses were received from female participants, and we were seeking to engage male participants in identifying and confirming solutions to the burden associated with shift work. Workshop participants comprised three nurses and two nurse unit managers. Participant's number of years working in a shift work role varied, ranging from two to 30 years' experience. The mean number of years working a shift work role was 14.6 years.

\section{MEASURES}

Participants completed an online wellbeing survey which assessed the following domains based on their previous association with shift work: physical health; physical activity engagement and preferences; diet and nutrition; health and wellbeing; alcohol and tobacco use; sleep; work roles and demographics. The survey included the K-6, a six-item measure which asks participants to rate each item on a five-point Likert-type scale. ${ }^{34}$ It is an abbreviated version of 
the K-10, and provided a measure of psychological distress drawing from depressive and anxiety related symptomology. The survey also included the AUDIT-C, a brief three-item alcohol screen that identifies hazardous drinking. ${ }^{35}$ Participants were asked how often they smoked cigarettes, as well as single Likert-type measures of general wellbeing and life-satisfaction. In addition to these general items, we also asked participants "How shift work had impacted on their overall wellbeing (either positively or negatively)? Participants provided written responses to this question ranging from a sentence to a paragraph of text.

The co-design workshop began with self-reflection about shift work, recorded in workbooks supplied to participants following presentation of the main survey results by the senior author. Consistent with recommendations for optimal group sizes, ${ }^{36,37}$ the number of workshop participants $(n=5)$ was selected to enhance comfort and facilitate active participation in the workshop. Larger workshop groups can be uncomfortable for some participants and can act as a barrier to sharing ideas and opinions. ${ }^{36}$ As is a common technique in co-design, we divided participants into two groups to further encourage active participation and engagement. ${ }^{37}$ We subsequently divided participants into two groups to allow participants to reflect on their work and internal discussions as best as possible around creating cognitive and contextual maps around identifying opportunities for intervention to improve health and wellbeing for shift workers. ${ }^{38}$

\section{DATA ANALYSIS}

Independent t-tests and chi-square tests were used to assess differences between shift workers and non-shift workers, and male and female shift workers for ratio and categoricallevel data. We next investigated open-ended survey and co-design workshop responses and qualitatively analysed them using the Framework approach to thematic analysis. ${ }^{38}$ This approach encourages themes to emerge inductively from the data in addition to being deductively derived from the study aims, therefore making it suitable for applied and practice relevant research. ${ }^{8}$ The first two authors initially coded a number of responses into themes. These were then discussed and additional themes added to the framework based on our knowledge of the literature, and a final thematic framework was agreed upon. Subsequent responses were coded by the first author using the thematic framework, and interpretations of the data further discussed by all authors. We also calculated the proportion of responses that were coded in each category and the overall number of positive and negative responses.

\section{RESULTS}

One thousand eight hundred and twelve survey attempts were recorded, with 1,398 containing data for $>75 \%$ of all fields
(579 shift workers, SW), which were retained for the present analysis. The majority of participants were female $(n=1,101$, 84.1\%; SW: $n=492,85 \%$ ), with 193 males (14.7\%, SW: $n=83,14.3 \%)$ and 15 others (1.1\%, SW: $n=4,0.7 \%)$. The age distribution of participants was as follows: ( $\leq 30$ years: $n=215$ (SW: $n=156$ ), 31-39: $n=237$ (SW: $n=91$ ), 40-49: $n=253$ (SW: $n=101$ ), 50-59: $n=309$ (SW: $n=115), 60+$ years: $n=70(S W: n=30), 275$ not stated (SW: $n=101)$. Table 1 describes the work and shift pattern of participants, with comparisons between shift workers and non-shift workers. Table 1 also shows that the majority of the sample were nurses, followed by medical and allied health professionals and corporate/administrators.

TABLE 1: WORK AND SHIFT PATTERN OF PARTICIPANTS COMPLETING THE "SHIFT-WORK-PLAY"

\begin{tabular}{|c|c|c|}
\hline & N (\%) non-SW & N (\%) SW \\
\hline \multicolumn{3}{|l|}{$\begin{array}{l}\text { Average weekly hours worked } \\
\text { (past month) }\end{array}$} \\
\hline 0 & $13(1.0)$ & $6(1.0)$ \\
\hline $1-40$ & $1,001(74.5)$ & $490(82.7)$ \\
\hline$>40$ & $311(24.5)$ & $98(16.3)$ \\
\hline \multicolumn{3}{|l|}{ Worked in current role } \\
\hline$\leq 5$ years & $719(63.9)$ & $297(52.3)$ \\
\hline $6-10$ years & $289(17.3)$ & $129(22.7)$ \\
\hline $11-15$ years & $105(8.5)$ & $60(10.6)$ \\
\hline $16-20$ years & $64(5.1)$ & $38(6.7)$ \\
\hline$>20$ years & $64(5.1)$ & $44(7.7)$ \\
\hline \multicolumn{3}{|l|}{ Currently a shift-worker } \\
\hline Yes & - & $594(44.8)$ \\
\hline No & $731(55.2)$ & - \\
\hline \multicolumn{3}{|l|}{ Role } \\
\hline Nursing & $597(45.1)$ & $463(77.9)$ \\
\hline Medical & $100(7.5)$ & $51(8.6)$ \\
\hline Allied health & $247(18.6)$ & $37(6.2)$ \\
\hline Other health & $42(3.2)$ & $7(1.2)$ \\
\hline Administration/Corporate & $193(14.6)$ & $31(5.2)$ \\
\hline Other & $146(11.0)$ & $5(0.9)$ \\
\hline $\begin{array}{l}\text { Types of shift worked in past } \\
\text { month }\end{array}$ & - & \\
\hline Day (6am-7pm) & & $500(84.2)$ \\
\hline Evening (3pm-12am) & & $493(83.0)$ \\
\hline Night (10pm-8am) & & $360(60.6)$ \\
\hline Freq. of night shifts (10pm-8am) & - & \\
\hline Nearly every day & & $16(2.8)$ \\
\hline 2-4 times per week & & $128(22.1)$ \\
\hline 3-4 times per month & & $132(22.8)$ \\
\hline 1-2 times per month & & $92(15.9)$ \\
\hline Rarely/Nearly never & & $211(36.4)$ \\
\hline Freq. of rotating shifts & - & \\
\hline Nearly every day & & $227(39.2)$ \\
\hline 2-4 times per week & & $133(23.0)$ \\
\hline 3-4 times per month & & $63(10.9)$ \\
\hline 1-2 times per month & & $55(9.5)$ \\
\hline Rarely/Nearly never & & $101(17.4)$ \\
\hline
\end{tabular}

SW=shift worker 
TABLE 2: DIFFERENCES IN WELLBEING, HEALTH, ALCOHOL USE AND PSYCHOLOGICAL DISTRESS BETWEEN SHIFT WORKERS AND NON-SHIFT WORKERS. MEAN (SD)

\begin{tabular}{|c|c|c|c|}
\hline Measure & Non-shift worker & Shift worker & Difference \\
\hline AUDIT-C & $3.18(1.83)$ & $3.44(1.96)$ & $t(1,170)=2.41, p=.016$ \\
\hline Smokers & Yes $=41(5.6 \%)$ & Yes $=53(8.9 \%)$ & $X^{2}(1 d f)=5.46, p=.019$ \\
\hline Overall Health & & & $X^{2}(4 d f)=14.46, p=.006$ \\
\hline Poor & $22(42.3)$ & $30(57.7)$ & \\
\hline Fair & $124(49.8)$ & $125(50.2)$ & \\
\hline Very Good & $256(59.1)$ & $177(40.9)$ & \\
\hline Excellent & $51(68.0)$ & $24(32.0)$ & \\
\hline$K-6$ & $4.13(3.90)$ & $4.57(4.09)$ & $t(1,323)=1.96, p=.05$ \\
\hline Life satisfaction & & & $X^{2}(2 d f)=1.66, p>.05$ \\
\hline Dissatisfied & $97(13.3 \%)$ & $76(12.8 \%)$ & \\
\hline Neutral & $59(8.1 \%)$ & $60(10.1 \%)$ & \\
\hline
\end{tabular}

TABLE 3: DIFFERENCES IN WELLBEING, HEALTH, ALCOHOL USE AND PSYCHOLOGICAL DISTRESS BETWEEN MALE AND FEMALE SHIFT WORKERS. MEAN (SD)

\begin{tabular}{|c|c|c|c|}
\hline Measure & Males $(n=76)$ & Females $(n=420)$ & Difference \\
\hline AUDIT-C & $4.08(2.31)$ & $3.18(1.83)$ & $t(494)=3.09, p=.002$ \\
\hline Smokers & Yes $=16(19.5 \%)$ & Yes $=54(11.0 \%)$ & $X^{2}(1 \mathrm{df})=4.75, p=.029$ \\
\hline \multicolumn{4}{|c|}{ Overall Health } \\
\hline Poor & $6(7.2)$ & $24(4.9)$ & $X^{2}(4 d f)=10.93, p=.027$ \\
\hline Fair & $27(32.5)$ & $91(18.5)$ & \\
\hline Very good & $20(24.1)$ & $154(31.3)$ & \\
\hline Excellent & $4(4.8)$ & $18(3.7)$ & \\
\hline$K-6$ & $5.13(4.08)$ & $4.46(4.02)$ & $t(573)=1.41, p>.05$ \\
\hline \multicolumn{4}{|c|}{ Life satisfaction } \\
\hline Dissatisfied & $15(18.1 \%)$ & $60(12.2 \%)$ & $X^{2}(2 d f)=2.165, p>.05$ \\
\hline Neutral & $8(9.6 \%)$ & $50(10.2 \%)$ & \\
\hline
\end{tabular}

Differences between shift workers and non-shift workers on measures of health, wellbeing, alcohol use and psychological distress are given in Table 2. Shift-workers were more likely than non-shift workers to report: higher AUDIT scores, being smokers, and overall poorer health.

Differences between male and female shift workers are provided in Table 3. Male shift-workers were more likely than female shift workers to report: higher AUDIT scores, being smokers, and overall poorer health.

\section{Positive and negative impacts of shift work}

In response to the open-ended statement on how shift work had impacted overall wellbeing, 615 statements were provided. Two broad main themes were identified including whether impacts were 'negative' $(493,80.2 \%)$ or whether impacts were 'positive' $(83,13.5 \%)$. In addition, 39 (6.3\%) responses were coded as 'neutral'. Figure 1 shows the frequency of sub-themes related to the 'negative' and 'positive' main themes.
There was not much overlap between positive and negative aspects of shift work. However, social elements featured in both groups. Other than this, the most common negative sub-themes centred on sleep, and health outcomes, while positive sub-themes centred on flexibility.

To further examine these differences, we examined the positive and negative statements based on gender and occupation (see Table 4). Female staff, and nurses were more likely to provide examples of both positive and negative aspects of shift work. 


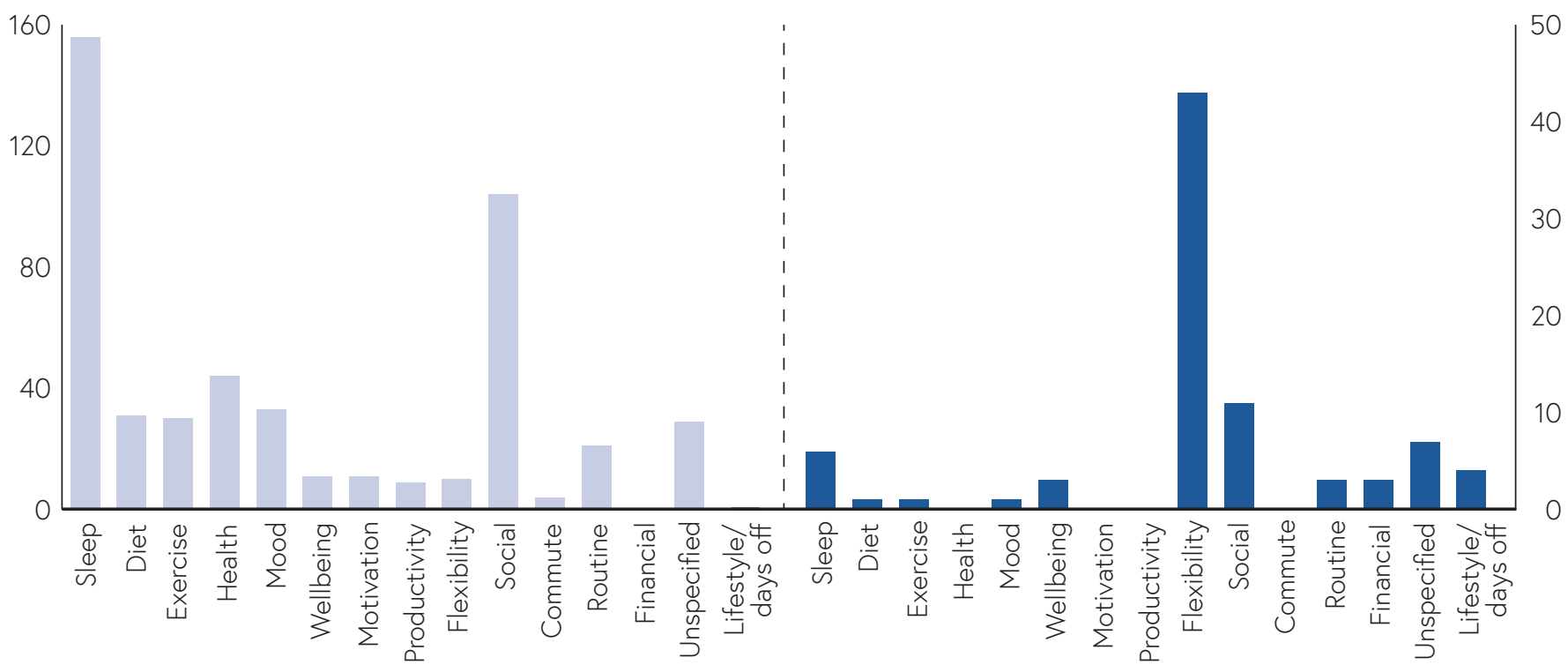

FIGURE 1. NUMBER OF POSITIVE AND NEGATIVE ELEMENTS ASSOCIATED WITH SHIFT WORK

TABLE 4: NUMBER OF POSITIVE AND NEGATIVE ASPECTS OF SHIFT-WORK BY GENDER (A) AND OCCUPATION (B)

\begin{tabular}{|c|c|c|}
\hline & Positive & Negative \\
\hline \multicolumn{3}{|c|}{ (A) Gender } \\
\hline Male & $14(16.9 \%)$ & 75 (15.4\%) \\
\hline Female & 69 (83.1\%) & 412 (84.6\%) \\
\hline Total & 83 & $487^{a}$ \\
\hline
\end{tabular}

\section{(B) Occupation}

\begin{tabular}{|l|r|r|}
\hline Nursing & $64(77.1 \%)$ & $397(80.5 \%)$ \\
Medicine & $5(6.0 \%)$ & $44(8.9 \%)$ \\
Allied health & $7(8.4 \%)$ & $21(4.3 \%)$ \\
Admin & $5(6.0 \%)$ & $21(4.3 \%)$ \\
Other & $2(2.4 \%)$ & $10(2.0 \%)$ \\
\hline Total & 83 & 493 \\
\hline
\end{tabular}

a Three negative comments were provided by staff who identified as non-binary, and three comments did not specify gender (data ns).

\section{NEGATIVE IMPACTS}

Sleep loss was consistently reported as a major negative aspect of shift work, which often subsequently impacted on other areas of life as illustrated by the following quotes with emphasis added by the researchers to denote themes.:

"My sleep pattern is disrupted and I wake up a couple of times even when I am not on call that night. I would prefer to sleep at the same time each day at around 10:30 pm. (Female, age 58, Allied Health)"

"I believe shift work has had a big negative impact because if I work an evening shift $\&$ then morning shift, I get a maximum of 5 \& 1/2 hours sleep. This makes me extremely tired." (Male, age 61, Nurse)
"I believe shift work has done significant damage to me (sic) sleep cycle. Because my body gets used to staying up/ being switched on until 11pm-12am on a late shift I find it hard to get to sleep on a day off. When I do am shifts, my body gets used to waking up at 5 am and on a day off I find it hard to sleep past that time. This has caused me to feel like I have chronic fatigue. Also, being on a rotating roster, I constantly worry I will forget to turn up for a shift, or turn up for a shift at the wrong time - this makes me very anxious on a constant basis..." (Female, age 32, Allied Health)

"Negatively as l'm getting older and I have less ability to cope with less sleep which impacts my health and mental wellbeing. I feel isolated from friends as l cannot participate in social events on weekends due to work so I slowly disengage from them and I feel they do not understand my circumstances." (Female, age 32, Nurse)

The first two of these quotes demonstrate the impact that shift work has on the underlying circadian system, with the third also noting that this can feed into mental health (anxiety)-related symptomology, while the latter notes the impact on one's ability to socialise.

\section{POSITIVE IMPACTS}

While participants predominantly reported negative impacts some also mentioned positive impacts. One of the main positive impacts noted centred upon flexibility, particularly with respect to services that can be difficult to engage with outside of business hours (e.g. banks, post-office), or childcare:

\section{"Positively when you get a longer stretch of time off} e.g.- early finish to a late start. Negatively when on a late early. Shift work also gives me more opportunity to access day time facilities - e.g. banks.”(Female, age not provided, Nurse) 
"Wasn't of benefit, now since having a child is more positive as this allows more flexibility e.g. taking weekdays off." (Male, age 30, nurse)

However, these positive outcomes were rarely mentioned in isolation, and tended to carry a cost or caveat, negatively affecting a person's ability to ensure healthy lifestyle habits such as diet and exercise:

"Some positive aspects of shift work are being able to do things when the crowds are not there, however the tiredness that comes from varied shift hours contributes to poor eating habits at times and inability to exercise consistently" (Female, age 6o, nurse)

\section{SOCIAL ASPECTS OF SHIFT WORK}

Interestingly, social aspects of shift work were viewed both positively (first two quotes), and negatively (second two quotes)"

"Does allow for more time spent with family outside of business hours, while maintaining a decent amount of worked hours" (Female, age 37, nurse)

"makes it easier to catch up with other nursing friends, but harder to catch up with other non-nursing friends and have lost friends because of this". (Female, age 27, nurse)

"It has impacted mostly negatively. When I do night shifts, I do not see my partner for a few weeks. When I work weekends. I do not have time to participate in social events with my friends. When I work morning shift. I feel too tired after I go home. I do not cook. And I need to nap for 2-3 hours." (Female, age 30, nurse)

"I constantly miss out on social family and friend gettogethers and people have to change their arrangements to try to include me. Changing rosters is difficult with limited ability to change so often I don't even try. Arrangements must be made at least 7-8 weeks in advance so being spontaneous is limited..."(Female, age not provided, nurse)

The positive impacts, again carried caveats and sometimes also emerged as negative impacts. For example, while shift work may have perceived positive impacts in terms of socialising or accessing services during quieter periods, they negatively impacted on relationships outside of work settings.

"Some positive aspects of shift work are being able to do things when the crowds are not there, however the tiredness that comes from varied shift hours contributes to poor eating habits at times and inability to exercise consistently". (Female, aged 6o, nurse)

\section{CO-DESIGN WORKSHOP: IDENTIFYING OPPORTUNITIES FOR MEN}

Given the dearth of literature that has examined male nurses despite negative health outcomes reported in a group of Australian and New Zealand males compared to females, ${ }^{29}$ and the relative increases in social isolation in males compared with females, we identified an opportunity to engage men through a physical activity program that could address issues related to physical health, sedentary behaviour, and provide opportunities to socialise with peers. Findings from the survey were first presented by the facilitator and viewed as consistent with the experiences of shift workers participating at the co-design workshop. Of particular note was the interconnection and often competing pressures identified in the qualitative analysis of survey responses. For example, participants endorsed the finding that shift work reduced opportunities to connect with friends and family, but also highlighted that they often wanted to sleep or have 'alone' time rather than socialise after completing a shift. The theme of exhaustion or fatigue following a shift also was linked to lack of motivation (or availability) to engage with services such as a gym which limited physical activity and led to poorer eating habits.

Participants saw an opportunity to address both their perceived lack of social connectedness and lack of exercise/ physical activity through a group-based physical activity to address loneliness and isolation for male shift workers in particular. A nurse unit manager who had been engaged in shift work for over 10 years stated that such an activity:

“...will reach a population of workers who otherwise might not know that there are 10 other guys just like him who are crying out for a shift work gym buddy" (Male, co-design participant).

Participants suggested that such a mechanism was a good way of promoting social connectedness, as group-based physical activity is able to provide opportunities for individuals to work on skills at their own pace, and derive broader health benefits through interacting with others. They supported the idea that increased socialisation can begin through attendance of an exercise group program, and could lead to further opportunities to socialise and reduce isolation. For instance, a clinical nurse who had been a shift worker for 26 years stated:

"A group-based exercise program will provide a vehicle for me to get active...it actually considers the stressors and pressures of a shift worker juggling work while also doing some good for my health. It'll help a number of us to get together before work to 'play"' (Male, co-design participant)."

\section{DISCUSSION}

The present study found that shift workers were more likely than their non-shift work counterparts to report poorer overall health, and to have higher levels of psychological distress, supporting findings of previous research. ${ }^{13,17}$ We also identified that shift workers also engaged in greater levels of unhealthy behaviours than non-shift workers, including higher alcohol consumption, and were more likely to be 
smokers. These results are concerning from an overall health standpoint given shift workers are reportedly more likely to engage in unhealthy patterns of alcohol consumption (e.g. binges), ${ }^{39}$ with a recent Australian study also reporting that many nurses do not adhere to healthy lifestyle recommendations regarding diet, exercise and alcohol use..$^{40}$ Taken together findings from both the current study and the previous literature have implications for long term health outcomes of shift workers, given alcohol's role in the burden of disease. ${ }^{41}$ These findings may also impact on productivity as alcohol consumption has been found to reduce subsequent work productivity especially in combination with night shifts. Higher rates of smoking in this shift work group are also of concern given the health consequences associated with smoking,,42 and that a recent report found that one third of shift workers reported smoking in order to stay awake. ${ }^{43}$ Smoking to stay awake in this study was associated with an increased propensity to make errors associated with fatigue, to report greater sleepiness, and to increase stress and burnout. ${ }^{43}$

\section{NEGATIVE IMPACTS LINK SLEEP TO WELLBEING AND OVERALL HEALTH}

Analysis of the shift work experience reported by participants in our study predominantly revealed negative impacts. More than four-in-five responses were coded as negative, and centred on poorer sleep and health outcomes. While reports of poor sleep in this group are not surprising given previous work in this area, 44,45 results of our study reinforce the important role of good sleep health, which has been postulated to significantly improve an individual's tolerance to shift work. ${ }^{24}$ Indeed, our present analysis revealed that sleep problems were rarely mentioned in isolation by shift workers, and were often reported in the context of other physical and mental health issues that they were experiencing. This finding supports literature demonstrating the complex interactions between these factors. ${ }^{12}$

\section{POSITIVE IMPACTS CAME WITH CAVEATS}

Interestingly, almost one-in-five responses provided by our participants revealed positive impacts of shift work on wellbeing, and overall life-satisfaction was not significantly different between shift workers and non-shift workers. This does not reflect the overall balance of literature which has focused on negative outcomes associated with these patterns. ${ }^{46}$ The majority of positive coded statements reflected elements associated with flexibility, ${ }^{47,48}$ such as the ability to engage with services that operate during business hours (e.g. banks, post office), or allowing for increased time with children, and decreased external childcare costs. Interestingly, some social elements were viewed as positive, particularly in the ability to socialise with other shift workers. However, the positive aspects of shift work tended to carry a cost, and were rarely presented without caveats or related negative impacts. For example, while socialisation was regarded as possible with other shift workers (as they were awake at the same time), it was also associated with less family time, and a decreased ability to attend social events outside the workplace, placing a large impact on home life.9,49 Additionally, while flexibility was viewed positively, the associated costs were often framed in terms of the three pillars of health as recognised by the National Sleep Foundation: sleep, diet, and exercise..$^{\circ}$ One important aspect of this is likely differences in individual physiology which may drive the perceived negative aspects of shift work. For example, a study in police officers reported that those who preferred longer spells of night shift work reporting that their experience of these shifts were less demanding, that they were able to have better sleep at different circadian phases, and more frequently identified as evening types..$^{51}$

\section{GENDER DIFFERENCES AND OPPORTUNITIES FOR INTERVENTION}

The present study also included a significant effort to address male shift workers' needs, given the lack of literature in this space. Consistent with the limited data available, we found increased risky alcohol use and smoking rates compared with females, and a greater likelihood to report poorer overall health. ${ }^{29}$ These findings are also consistent with previous work demonstrating greater utilisation of sick leave by male compared with female nurses..$^{30}$ Programs that tackle multiple areas of burden (socialisation, physical activity and wellbeing) were received positively. Indeed, given the health, performance and negative social consequences associated with shift work interventions that operate at multiple levels involving both organisations and individuals that simultaneously target many outcomes (sleep, diet, exercise, opportunities to connect with peers) are likely to be more effective than any individual measure. ${ }^{52}$

\section{CHALLENGES FOR IMPLEMENTATION}

This also highlights the difficulty in implementing effective health-related interventions, ${ }^{53}$ and organisational driven responses. For example, use of non-pharmacological measures to counter sleep issues is commonly recommended for shift workers (e.g. light therapy and opportunities for naps for the individual, and better rostering for organisations), ${ }^{54}$ or recommendations to implement education about the links between shift work, poor sleep and metabolic disorders. 55 Results from both components of the present study suggest that countermeasures for shift work may be best conceptualised as holistic, especially in targeting multiple, interconnected behaviours. Indeed, previous research reported limited efficacy when employees were allowed to self-select their work shifts, as people tended to consider both individual impacts on their own health and family as well as their organisations. ${ }^{6}$ By contrast, the present study suggests combining these competing needs by scheduling interventions complementary to the shift work period. A group-based opportunity for physical activity 
(facilitated and scheduled at different times to suit shift workers' schedules), that allows for individual attainment of exercise goals, but also affords opportunities for socialisation, was seen as a positive and systematic approach to be explored. Indeed, such a program could also incorporate education on healthy sleep and diet as demonstrated to be effective in previous studies. ${ }^{57} \mathrm{~A}$ recent systematic review reported that training emergency services personnel and other shift workers about fatigue and its consequences can improve health and safety outcomes,,$^{11}$ and the present study suggests that embedding this within a physical activity may provide a holistic approach to improve shift worker health and wellbeing. ${ }^{57}$ Interventions that focus on physical activity rather than explicitly focussing on mental health may be more palatable to men in particular given traditional masculine norms around stoicism and stigma associated with seeking help for mental health issues. ${ }^{58}$

\section{LIMITATIONS AND FUTURE DIRECTIONS}

The survey used self-assessment of physical and health outcomes, and may be subject to a non-report bias which affects the generalisability of the study results. However, previous studies using both cross-sectional and prospective designs have reported similar outcomes with respect to shift workers, and non-shift workers, and in addition to our qualitative work we embedded validated tools such as the K-6 and AUDIT-C to evaluate study outcomes, allowing comparison with previous work. A further limitation is the multitude of organisational and individual factors which impact working hours including occupation (e.g. doctors and nurses work different shifts, and this can vary even between different wards because of operational factors), and any intervention study aimed at shift working cohorts should consider this in addition to other factors such as gender discussed in this manuscript.

While the number of participants in the co-design workshop was small and limited to male participants, the experience and role of shift workers that participated allowed for representation across different levels of the hospital hierarchy, and participants did endorse the survey's main findings. This is important given that in order to make changes to complex and entrenched social issues or systems (such as hospital bureaucracies) we need to have conversations that incorporate the experiences of all involved from a different lens to that which is captured only using survey methods. Additionally, despite being crosssectional in design, the qualitative arm of the survey allowed for coding of $>500$ statements about the positive and negative elements of shift work. The large number of completed open-ended responses and the length of responses (as long as a paragraph in some instances) highlights high levels of participant engagement and the value of the data in terms of generating a large number of relatively rich insights.
However, other study designs including longitudinal studies containing interviews over time may provide in-depth data and an opportunity for further exploration and follow-up questioning that is not possible through surveys, and could be conducted with larger and/or more diverse groups. Future studies could also include prospective work to examine how changes in shifts are associated with outcomes over time, and also evaluate the feasibility of running organisationallevel responses to enhance shift workers health (such as the physical activity component) to complement existing education on sleep and general health.

\section{CONCLUSION}

Shift work has both positive negative impacts that affect individual health and wellbeing, as well as performance. These decrements are of particular relevance to nurses given that they are responsible for patient care and recovery 24 -h a day, seven days a week. Furthermore, our study highlights the importance of considering gender differences in both individual and organisational-level responses to address shift work in nursing settings.

\section{IMPLICATIONS FOR RESEARCH, POLICY, AND PRACTICE}

While there are some positive aspects associated with shift work, in order to effectively address the negative aspects, interventions that operate at multiple levels involving both organisations and individuals that simultaneously target multiple outcomes (sleep, diet, exercise, opportunities to connect with peers) are likely to be more effective than individual measures alone. This supports a recent review that noted that fatigue management interventions for nurses is currently fragmented and lacks overall cohesion. ${ }^{6}$

Acknowledgement: The authors would like to thank Sally Thomas, Josette O’Donnell, and Melissa Elliott from Eastern Health who contributed to the survey and co-design workshop development. The authors thank the participants who completed the survey and co-design workshop.

Funding support: RPO was supported by a Peter Doherty fellowship from the NHMRC (Australia). The project received funding from the Movember Foundation (Social Innovators Challenge).

Declaration of Competing Interests: DIL has received speaking honoraria from AstraZeneca, Camurus, Janssen, Servier and Lundbeck, and has provided consultancy advice to Lundbeck and Indivior. All other authors report no conflicts. 


\section{REFERENCES}

1. Australian Bureau of Statistics (ABS). Australian labour market statistics. Australian Bureau of Statistics. Canberra. 2010. Available from: https://www.abs.gov.au/AUSSTATS/abs@.nsf/ DetailsPage/6105.0Jan\%202010?OpenDocument

2. Golden L. Irregular work scheduling and its consequences (Briefing Paper 394). 2005. Economic Policy Institute. Washington DC, USA.

3. Morphet J, Kent B, Plummer V, Considine J. Profiling nursing resources in Australian emergency departments. Australas Emerg Nurs J. 2016: 19(1), 1-10

4. Ferguson SA, Kennaway DJ, Baker A, Lamond N, Dawson D. Sleep and circadian rhythms in mining operators: limited evidence of adaptation to night shifts. Appl Ergonom. 2012; 43(4): 695-701

5. Dorrian J, Baulk SD, Dawson D. Work hours, workload, sleep and fatigue in Australian Rail Industry employees. Appl Ergonom. 2011; 42(2), 202-9

6. Querstret D, O'Brien K, Skene DJ, Maben J. Improving fatigue risk management in healthcare: a systematic scoping review of sleep-related/fatigue-management interventions for nurses and midwives. Int J Nurs Stud. 2019; 106: 103513

7. Jensen HI, Larsen JW, Thomsen TD. The impact of shift work on intensive care nurses' lives outside work: a cross-sectional study. J Clin Nurs, 2017; 27: e707-709.

8. Rosa D, Terzoni S, Dellafiore F, Destrebecq A. Systematic review of shift work and nurses' health. Occupat Med. 2019; 69(4), 237-43.

9. Di Simone E, Di Muzio M, Dionisi S, Giannetta N, Di Muzio F, De Gennaro L. et al. Infoedipemiological patterns in searching medication errors: relationship with risk management and shift work. Eur Rev Med Pharmacol Sci. 2019; 23(12), 5522-9.

10. Gander P, O'Keefe K, Santos-Fernandez E, Huntington A, Walker $L$, Willis J. Fatigue and nurses' work patterns: an online questionnaire survey. Int J Nurs Stud. 2019; 98: 67-74.

11. Clendon J, Gibbons V. 12h shifts and rates of error among nurses: a systematic review. Int J Nurs Stud. 2015; 52: 1231-42.

12. Rajaratnam SMW, Arendt J. Health in a 24-h society. Lancet. 2001; 358(9286): 999-1005.

13. Kecklund G, Axelsson J. Health consequences of shift work and insufficient sleep. BMJ. 2016; 355: i5210.

14. Bøggild H, Knutsson A. Shift work, risk factors and cardiovascular disease. Scand J Work Environ Health. 1999; 25(2): 85-99.

15. Vetter C, Devore EE, Ramin CA, Speizer FE, Willett WC, Schernhammer ES. Mismatch of sleep and work timing and risk of type 2 diabetes. Diabetes Care. 2015; 38(9):1707-13.

16. Harrington JM. Health effects of shift work and extended hours of work. Occup Environ Med. 2001; 58(1): 68-72.

17. Matheson A, O'Brien L, Reid JA. The impact of shiftwork on health: a literature review. J Clin Nurs. 2014; 23(23-24): 3309-20.

18. Barnes-Farrell JL, Davies-Schrils K, McGonagle A, Walsh B, Milia $L D$, Fischer $F$, et al. What aspects of shiftwork influence off-shift well-being of healthcare workers? Appl Ergonom. 2008; 39(5): 589-96.

19. Barger LK, Lockley SW, Rajaratnam SMW, Landrigan CP. Neurobehavioral, health, and safety consequences associated with shift work in safety-sensitive professions. Curr Neurol Neurosci Rep. 2009; 9(2): 155-64.
20. Dall'Ora C, Ball J, Recio-Saucedo A, Griffiths P. Characteristics of shift work and their impact on employee performance and wellbeing: a literature review. Int J Nurs Stud. 2016; 57: 12-27.

21. Berger AM, Hobbs BB. Impact of shift work on the health and safety of nurses and patients. Clin J Oncol Nurs. 2006; 10(4): 465-71.

22. Nabe-Nielsen K, Garde AH, Clausen T, Torgensen MB. Does workplace health promotion reach shift workers? Scand J Work Environ Health. 2015; 41(1): 84-93.

23. Foldal VS, Langvik E, Saksvik-Lehouillier I. Personal dispositions and shift-work tolerance: a longitudinal study of municipality shift workers. J Employ Couns. 2016; 53(4): 174-86.

24. Saksvik IB, Bjorvatn B, Hetland H, Sandal GM, Pallesen S. Individual differences in tolerance to shift work - a systematic review. Sleep Med Rev. 2011; 15(4): 221-35.

25. Saksvik-Lehouillier I, Bjorvatn B, Magerøy N, Pallesen S. Hardiness, psychosocial factors and shift work tolerance among nurses - a 2-year follow-up study. J Adv Nurs. 2016; 72(8): 1800-12.

26. Ha EH. Attitudes towards rotating shift work in clinical nurses: a Q-methodology study. J Clin Nurs. 2015; 24: 2488-97.

27. Lim S, Han K, Cho H, Baek H. Shift-work nurses' work environments and health-promoting behaviours in relation to sleep disturbance: a cross-sectional secondary data analysis. J Clin Nurs. 2018; 28: 1538-45.

28. Eng A, Mannetje A, McLean D, Ellison-Loschmann L, Cheng S, Pearce N. Gender differences in occupational exposure patterns. Occup Environ Med. 2011; 68(12): 888.

29. Tuckett A, Henwood T, Oliffe JL, Kolbe-Alexander TL, Kim JR. A comparative study of Australian and New Zealand male and female nurses' health: a sex comparison and gender analysis. Am J Men's Health. 2015; 10(6): 450-8.

30. Evans $\mathrm{O}$, Steptoe A. The contribution of gender-role orientation, work factors and home stressors to psychological wellbeing and sickness absence in male- and female-dominated occupational groups. Soc Sci Med. 2002; 54(4): 481-92.

31. Oliffe JL, Broom A, Popa M, Jenkins EK, Rice SM, Ferlatte O, et al. (2019). Unpacking social isolation in men's suicidality. Qual Health Res. 2019; 29: 315-27.

32. Orlowski SK, Lawn S, Venning A, Winsall M, Jones GM, Wyld $K$, et al. Participatory research as one piece of the puzzle: a systematic review of consumer involvement in design of technology-based youth mental health and well-being interventions. JMIR Hum Fact. 2015; 2(2): e12.

33. Steen M, Manschot M, De Koning N. Benefits of co-design in service design projects. Int J Design. 2011; 5(2): 53-60.

34. Kessler RC, Green JG, Gruber MJ, Sampson NA, Bromet E, Cuitan $M$, et al. Screening for serious mental illness in the general population with the $\mathrm{K} 6$ screening scale: results from the WHO World Mental Health (WMH) survey initiative. Int J Meth Psychiat Res. 2010; 19(S1): 4-22.

35. Bradley KA, DeBenedetti AF, Volk RJ, Williams EC, Frank D, Kivlahan DR. AUDIT-C as a brief screen for alcohol misuse in primary care. Alcohol Clin Exp Res. 2007; 31(7): 1208-17.

36. Krueger RA, Casey MA. Focus groups: a practical guide for applied research. Sage Publications; 2004.

37. CO-CREATE Consortium. The CO-CREATE Handbook for creative professionals. CO-CREATE Consortium. 2019. Available from: http://www.cocreate.training/wp-content/ uploads/2019/03/co-design handbook FINAL.pdf 
38. Ritchie J, Spencer L, O'Connor W. Carrying out qualitative analysis. In Ritchie J, Lewis J, editors. Qualitative Research Practice. London: Sage Publications; 2003; 219-62.

39. Dorrian J, Heath G, Sargent C, Banks S, Coates A. Alcohol use in shiftworkers. Accid Anal Prev. 2015; 99: 395-400.

40. Heidke P, Madsen WL, Langham EM. Registered nurses as role models for healthy lifestyles. Aust J Adv Nurs. 2020, 37(2).

41. Ogeil RP, Gao CX, Rehm J, Gmel G, Lloyd B. Temporal changes in alcohol-related mortality and morbidity in Australia. Addiction. 2016; 111(4): 626-34.

42. Reitsma MB, Fullman N, Ng M, Salama JS, Abajobir A, Abate KH, et al. Smoking prevalence and attributable disease burden in 195 countries and territories, 1990-2015: a systematic analysis from the Global Burden of Disease Study 2015. Lancet. 2017; 389(10082); 1885-906.

43. Ogeil RP, Barger LK, Lockley SW, O'Brien CS, Sulliivan JP, Qadri S, Rajaratnam SMW. Cross-sectional analysis of sleep-promoting and wake-promoting drug use on health, fatigue-related error, and near-crashes in police officers. BMJ Open. 2018; 8(9): e022041.

44. Åkerstedt, T. Shift work and disturbed sleep/wakefulness. Occupat Med. 2003; 53(2): 89-94.

45. McDowall K, Murphy E, Anderson K. The impact of shift work on sleep quality among nurses. Occupat Med. 2017; 67(8): 621-25.

46. Caruso CC. Negative impacts of shiftwork and long work hours. Rehab Nurs. 2014; 39(1): 16-25.

47. Dhaini SR, Denhaerynck K, Bachnick S, Schwendimann R, Schubert M, De Geest S, et al. Work schedule flexibility is associated with emotional exhaustion among registered nurses in Swiss hospitals: a cross-sectional study. Int J Nurs Stud. 2018; 82: 99-105.

48. Gifkins J, Loudoun R, Johnston A. Coping strategies and social support needs of experienced and inexperienced nurses performing shiftwork. J Adv Nurs. 2017; 73(12): 3079-89.

49. Vitale SA, Varrone-Ganesh J, Vu M. Nurses working the night shift: impact on home, family and social life. J Nurs Edu Prac. 2015; 5(10)

50. Lopresti AL, Hood SD, Drummond, PD. A review of lifestyle factors that contribute to important pathways associated with major depression: diet, sleep and exercise. J Aff Disord. 2013; 148(1): 12-27.

51. Nabe-Nielsen K, Aarrebo Jensen M, Hansen AM, Kristiansen J, Garde $\mathrm{AH}$. What is the preferred number of consecutive night shifts? results from a crossover intervention study among police officers in Denmark, Ergonomics. 2016. 59(10), 1392-402.

52. Cheng P, Drake C. Shift work and work performance. In: Work and sleep: research insights for the workplace. 2016; 11-30.

53. Neil-Sztramko SE, Pahwa M, Demers PA, Gotay CC. Healthrelated interventions among night shift workers: a critical review of the literature. Scand J Work Environ Health. 2014; 40(6): 543-56.

54. Richter K, Acker J, Adam S, Niklewski G. Prevention of fatigue and insomnia in shift workers-a review of non-pharmacological measures. EPMA Journal. 2016; 7(1), 16.

55. Givens M L, Malecki KC, Peppard PE, Palta M, Said A, Engelman $C D$, et al. Shiftwork, sleep habits, and metabolic disparities: results from the survey of the health of Wisconsin. Sleep Health. 2015; 1(2): 115-20.

56. Nabe-Nielsen K, Lund H, Ajslev J, Hansen AM, Albertsen K, Hvid $\mathrm{H}$, et al. How do employees prioritise when they schedule their own shifts? Ergonomics. 2013. 56(8), 1216-24.
57. Barger LK, Runyon MS, Renn ML, Moore CG, Weiss PM, Condle $J P$, et al. Effect of fatigue training on safety, fatigue, and sleep in emergency medical services personnel and other shift workers: a systematic review and meta-analysis. Prehosp Emerg Care. 2018; 22(s1).

58. Addis ME, Mahalik JR. Men, masculinity, and the contexts of help seeking. Am Psychol. 2003; 58(1): 5-14. 